\title{
A Possible Connection of Midlatitude Mesosphere/Lower Thermosphere Zonal Winds and the Southern Oscillation
}

\author{
Christoph Jacobi and Dierk Kürschner
}

\section{Summary:}

Collm $\left(52^{\circ} \mathrm{N}, 15^{\circ} \mathrm{E}\right)$ midlatitude mesosphere/lower thermosphere (MLT) zonal winds are investigated with respect to a possible influence of the Southern Oscillation (SO). It is found that in winter the prevailing wind is positively correlated with the Southern Oscillation index (SOI), which qualitatively fits to the response of the low-latitude stratosphere on the SO. In summer, however, there is a negative correlation between MLT zonal winds and SOI. A possible mechanism, which includes slightly enhanced planetary wave propagation to the MLT in summers of low SOI is discussed.

\section{Zusammenfassung:}

Windmessungen aus Collm $\left(52^{\circ} \mathrm{N}, 15^{\circ} \mathrm{E}\right)$ wurden hinsichtlich eines möglichen Einflusses der Southern Oscillation (SO) in ihnen untersucht. Es zeigt sich, dass im Winter der mittlere Zonalwind positiv mit dem "Southern Oscillation Index" SOI korreliert ist, was qualitativ mit der Reaktion der Stratosphäre auf ENSO übereinstimmt. Im Sommer findet sich jedoch ein negativer Zusammenhang zwischen hochatmosphärischem Zonalwind und SOI. Ein möglicher Mechanismus, der die Ausbreitung planetarer Wellen beinhaltet, wird diskutiert.

\section{Introduction}

The Southern Oscillation (SO), often considered in connection with El Niño and thus abbreviated ENSO, is one of the strongest signals of the tropical atmosphere, which influences also extratropical regions. The SO is a seesaw in surface pressure between the tropical Indian Ocean/eastern Pacific and the other parts of the tropical Pacific, which influences tropospheric temperature and other climate parameters on a global scale. A typical period range of the connected oscillation is 3 - 4 years.

The SO also influences the stratosphere, as has been shown by van Loon and Labitzke (1987). During so-called "warm events" of the SO in winter the Aleutian high is intensified and the stratospheric polar vortex is disturbed. The reason for that is that during warm events the warm Pacific sea surface then leads to stronger convection in the tropics, thus stronger radiation from the cloud tops in the lower stratosphere and a colder tropical stratosphere then (e.g. Labitzke, 1999).

As the SO has some influence upon the stratosphere, it can be assumed that it also influences the upper layers of the middle atmosphere, namely the mesosphere/lower thermosphere (MLT) region around $70-110 \mathrm{~km}$ altitude, which is dynamically connected with the stratosphere e.g. through planetary and gravity wave propagation. MLT wind variations in the period range of 2 - 5 years were reported by Namboothiri et al. $(1993,1994)$ using the Saskatoon, Canada, medium frequency (MF) radar data. Oscillations with periods of $2-5$ years were also found within time series of the prevailing wind by Portnyagin (1986) and 
Portnyagin et al. (1993). Also recently, Kane et al (1999), using an extended database of Saskatoon winds, found variations in the 3-4 years band and speculated that these may be due to an influence of ENSO. Gavrilov et al. (1999) have found some interannual variability in gravity wave activity which they claimed to partially being due to ENSO. Investigating time series of MU radar mesospheric winds over Shigaraki, Japan $\left(35^{\circ} \mathrm{N}\right)$ they found during times of El Niño weaker westerlies or stronger easterlies in winter and summer, respectively.

To investigate, whether the ENSO signal is also visible in the mesosphere/lower thermosphere (MLT) region we investigate wind data from the long-term measurements over Collm, Germany. This is one of the very few MLT wind time series that extend over more than one decade. One has to be aware that results from one single point measurement can possibly not be assigned to the whole MLT and regional differences may be present. So, for instance, Jacobi et al. (2000) showed that there are considerable differences in the year-to-year variation of MLT winds over Canada and Europe at the same latitude. Therefore the results from Collm winds alone can only be attributed to the MLT region over Europe.

\section{Data}

The horizontal wind field of the mesosphere/lower thermosphere region over Collm, Germany, is continually observed by daily D1 radio wind measurements in the LF range, using the ionospherically reflected sky wave of three commercial radio transmitters on 177, 225 and $270 \mathrm{kHz}$. The measurements are carried out according to the closely-spaced receiver technique. A modified form of the similar-fade method is used (Schminder and Kürschner, 1994). The procedure is based on the estimation of time differences between corresponding fading extrema of the ionospherically reflected LF sky wave for three measuring points forming a right angled triangle over the ground with small sides of $300 \mathrm{~m}$ in direction $\mathrm{N}$ and $\mathrm{E}$, respectively. The individual pairs of time differences which allow the calculation of individual wind vectors are measured at a temporal resolution of $0.25 \mathrm{~s}$.

The individual wind measurements are combined to half-hourly zonal and meridional mean wind values on each frequency, with a mean value being averaged over 30 - 60 data points per frequency. The 1- $\sigma$ variation of the half-hourly mean is in the order of $20 \mathrm{~ms}^{-1}$, caused by the real wind variations and the uncertainties and number of the individual wind measurements. Since 1979, in order to improve the statistical reliability of the results, including the results of the individual measurements on each of the three frequencies combined with a weighting function based on an estimate of the "chaotic velocity" (Sprenger and Schminder, 1969), mean values are calculated, referring to a reflection point at $52^{\circ} \mathrm{N}, 15^{\circ} \mathrm{E}$. Since during the daytime the absorption of the sky wave is large, the measuring density decreases strongly then and especially in summer at times no half-hourly means can be constructed during the daytime. This results in a total of about 700 half hourly mean values per month in summer, and about 1200 in winter.

The prevailing wind calculations are based on half-hourly horizontal wind measurements at the mean measured reflection height of low-frequency radio waves. Thus, the measurements use total reflection of the LF radio waves, so that at any time wind measurements are possible only at one specific height. However, since this height changes during the day (e.g. Kürschner et al., 1987) and also from day to day it is possible to calculate monthly mean profiles of wind 
parameters between about 85 - $105 \mathrm{~km}$ (depending on season) using a regression analysis with quadratically height-dependent parameters, which takes into account the semidiurnal tide:

$$
\begin{array}{r}
\mathrm{v}_{\mathrm{z}}=\sum_{\mathrm{k}=0}^{\mathrm{p}}\left\{\mathrm{h}^{\mathrm{k}} \mathrm{a}_{\mathrm{k}, \mathrm{z}}+\mathrm{b}_{\mathrm{k}, \mathrm{z}} \mathrm{h}^{\mathrm{k}} \sin \omega \mathrm{t}+\mathrm{c}_{\mathrm{k}, \mathrm{z}} \mathrm{h}^{\mathrm{k}} \cos \omega \mathrm{t}\right\}, \\
\mathrm{v}_{\mathrm{m}}=\sum_{\mathrm{k}=0}^{\mathrm{p}}\left\{\mathrm{h}^{\mathrm{k}} \mathrm{a}_{\mathrm{k}, \mathrm{m}}+\mathrm{b}_{\mathrm{k}, \mathrm{m}} \mathrm{h}^{\mathrm{k}} \sin \omega \mathrm{t}+\mathrm{c}_{\mathrm{k}, \mathrm{m}} \mathrm{h}^{\mathrm{k}} \cos \omega \mathrm{t}\right\},
\end{array}
$$

with $\mathrm{p}=2, \omega$ as the angular frequency of the semidiurnal tide, and $\mathrm{h}$ being estimates of the real reflection height, which is calculated from the virtual reflection height using realistic electron density profiles (e.g. Jacobi et al., 1997). The virtual reflection heights are estimated using measured travel time differences between the ground wave and the reflected sky wave by means of phase comparisons in the modulation frequency range on $1.8 \mathrm{kHz}$ of the amplitude modulated LF radio wave (Kürschner et al., 1987).

The reflection height measurements have begun in September 1982 and are, as well as the wind measurements, carried out continuously since. Therefore mean profiles of MLT wind parameters can be obtained since then, whereas the measurements before late 1982 can only be interpreted in terms of the wind field of the maximum measurement density height near 95 $\mathrm{km}$. For this purpose Eqs. 1 and 2 are applied without height dependence, i.e. with $\mathrm{p}=0$ to the monthly median half-hourly wind values. In the following we shall shortly present long-term mean zonal prevailing wind profiles, but in order to extend the time series back to 1979 for trend estimations we shall use the monthly mean winds calculated without height dependence of the regression coefficients.

In order to improve the separation and the spectral selectivity of the evaluation of the tidal components, we make use of the circular polarization of the tide (Kürschner, 1991; Jacobi et $a l ., 1999)$ to calculate the tidal amplitudes and phases, thus

$$
\mathrm{b}_{\mathrm{k}, \mathrm{m}}=-\mathrm{c}_{\mathrm{k}, \mathrm{z}} \text {, and } \mathrm{c}_{\mathrm{k}, \mathrm{m}}=\mathrm{b}_{\mathrm{k}, \mathrm{z}} \text {. }
$$

The polarisation of the tidal components was proved e.g. by Jacobi et al. (1999) comparing tidal components measured independently at several northern midlatitude stations. The zonal prevailing wind is calculated after:

$$
\mathrm{v}_{\mathrm{oz}}(\mathrm{h})=\sum_{\mathrm{k}=0}^{\mathrm{p}} \mathrm{h}^{\mathrm{k}} \mathrm{a}_{\mathrm{k}, \mathrm{z}}
$$

This procedure is described, for example, by Kürschner and Schminder (1986) and Jacobi et al. (1997). Using this method, also combined profiles of winds from the Collm LF D1 measurements and the Juliusruh MF radar of the IAP Kühlungsborn are regularly calculated (e.g. Schminder et al., 1997).

For describing the SO using one single time series the Southern Oscillation Index (SOI) is frequently used. There exist several slightly different methods in calculating the SOI. It is taken here as the difference of the normalised Darwin and the normalised Tahiti sea level pressure anomaly (Trenberth, 1984; Ropelewski and Jones, 1987). Note that low SOI values mean strong pressure differences across the Pacific, weaker trade-winds and thus warmer sea-surface temperatures over the eastern Pacific. El Niño events are connected with low SOI. 


\section{Results}

\subsection{Zonal prevailing winds over Collm}

In Figure 1 winds from the HWM93 empirical wind model (Hedin et al., 1996) are shown for winter (December - February, DJF) and summer (June - August, JJA) for $52^{\circ} \mathrm{N}$ latitude. In the MLT region the respective Collm zonal winds are added. The Collm data are 1983 - 1998 mean values.

Height measurements at Collm are only available since 1983. To obtain an extended time interval, in the following winds calculated without height dependence are used, which can be attributed to the height of the maximum measuring density near $95 \mathrm{~km}$. In Figure 2 the times series for JJA and DJF means are shown together with the respective SOI values. Comparing the Collm winds with the Shigaraki MU radar data (Gavrilov et al., 1999, their Figure 1) it can be seen that, despite the longitudinal and latitudinal difference, some similarities are found, particularly the 1992 minimum in winter is found in both time series, and in the 1990s the Collm summer westerly winds are increasing, which corresponds to the decreasing of the easterly winds over Shigaraki after 1992.

The correspondence between SOI and MLT zonal winds is visible in the winter time series, e.g., in the corresponding minima in 1983, 1992, and 1998. The summer time series appear to be less strongly correlated, but a weak anticorrelation may be visible in the upper part of Figure 2. In addition, a positive long-term trend is visible in the MLT zonal winds with an increase of the westerly winds of $0.51 \mathrm{~ms}^{-1} \mathrm{yr}^{-1}$ in summer and $0.29 \mathrm{~ms}^{-1} \mathrm{yr}^{-1}$ in winter, which is not found in the SOI time series.
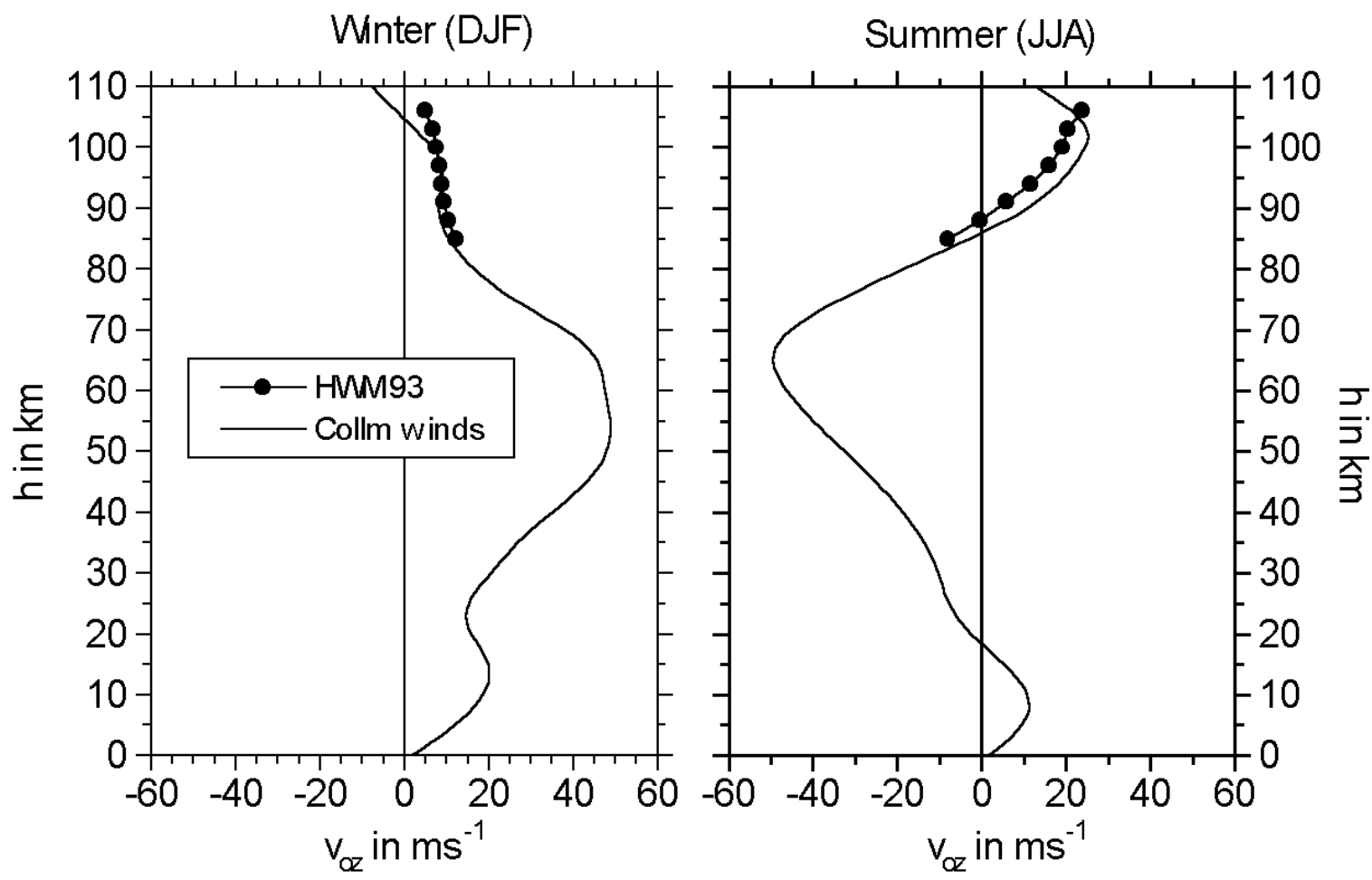

Figure 1: Mean winter (left panel) and summer (right panel) zonal prevailing wind profiles for $52^{\circ} \mathrm{N}$ from the HWM93 model and from LF D1 measurements over Collm. 


\subsection{The connection between $S O$ and MLT zonal winds}

To show the connection between $\mathrm{v}_{\mathrm{oz}}$ and SOI, the correlation coefficients between these parameters are shown in Figure 3 for each month of the year. A clear seasonal cycle is visible, although the correlation is not very strong in most months. However, at least during most of the winter the correlation is significant (t-test, see dotted lines in Figure 3).

It has been shown by several authors, and this is also confirmed by the results presented in Figure 2, that the MLT wind parameters exhibit considerable long-term trends and decadal variations, which are possibly owing to long-term atmospheric variability in connection with greenhouse gas emissions and extraterrestrial forcing in the frame of the 11-year solar cycle (e.g. Namboothiri et al., 1993; Bremer et al., 1997; Jacobi et al., 2000). As these signals not necessarily are found in the SO, we apply a high-pass filter by investigating the year-to-year differences of the MLT zonal winds and the SOI. The respective correlation coefficients for these data are also shown as open symbols in Figure 3. It can be seen that in summer the correlation is stronger than if one uses the unfiltered time series. In addition, we also correlated the SOI values of the respective months with the $\mathrm{v}_{\mathrm{oz}}$ values one month later (crossed symbols). This appears to be reasonable if we may assume that in summer planetary wave (PW) propagation during different phases of the SO may play a role in the possible troposphere-mesosphere-lower thermosphere coupling process, and the waves may need some time to propagate to the lower thermosphere. The correlation is much stronger now for June and July. In winter there is no strong difference when using either filtered or unfiltered time series, because the winter $\mathrm{v}_{\mathrm{oz}}$ long-term trend is weaker than the summer one so that the filter will only weakly influence the overall variability.

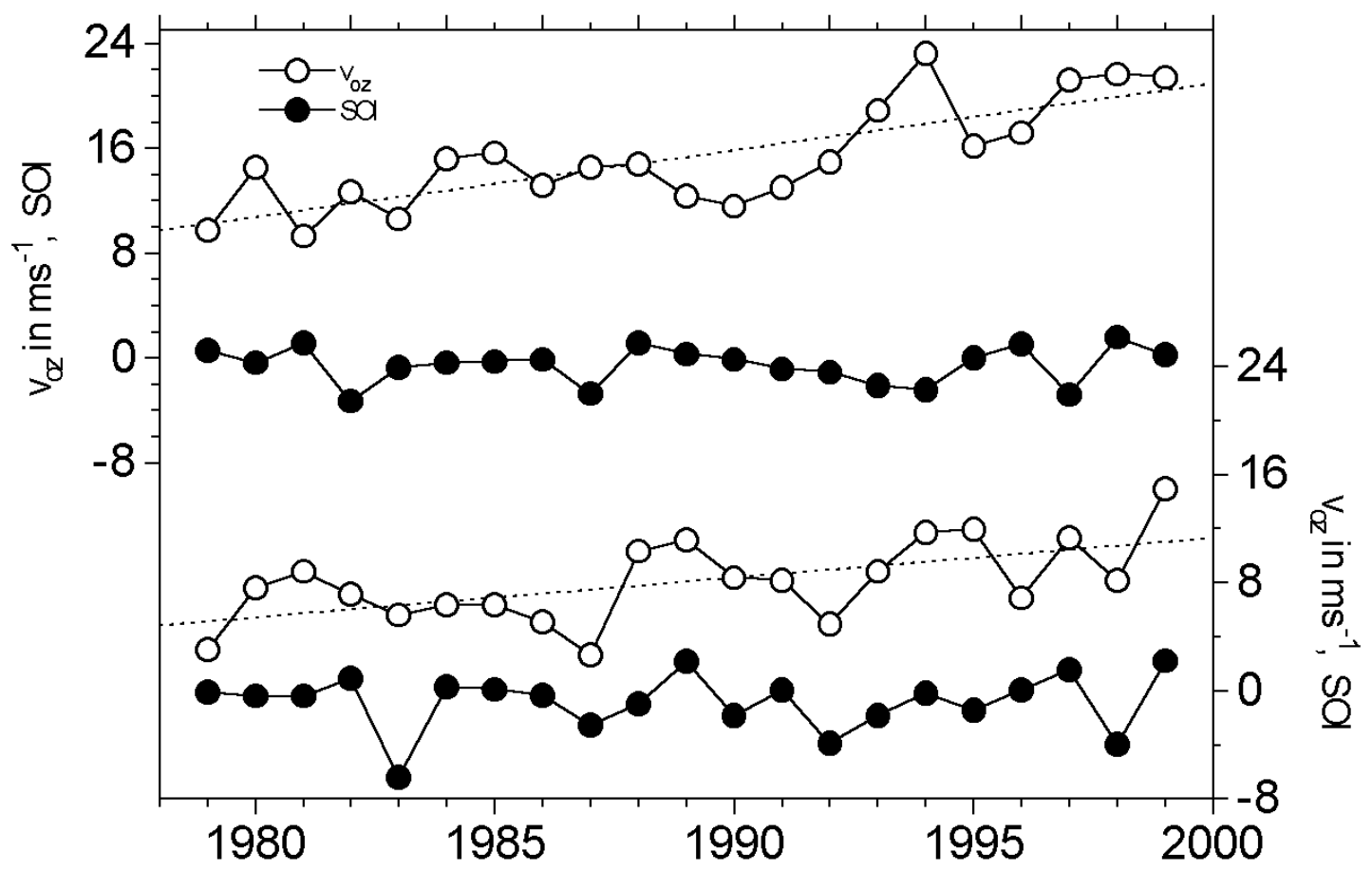

Figure 2: Time series of summer (JJA, upper part of figure) and winter (DJF, lower part of figure) zonal prevailing winds $v_{\text {oz }}$ near $95 \mathrm{~km}$ and $S O I$. 


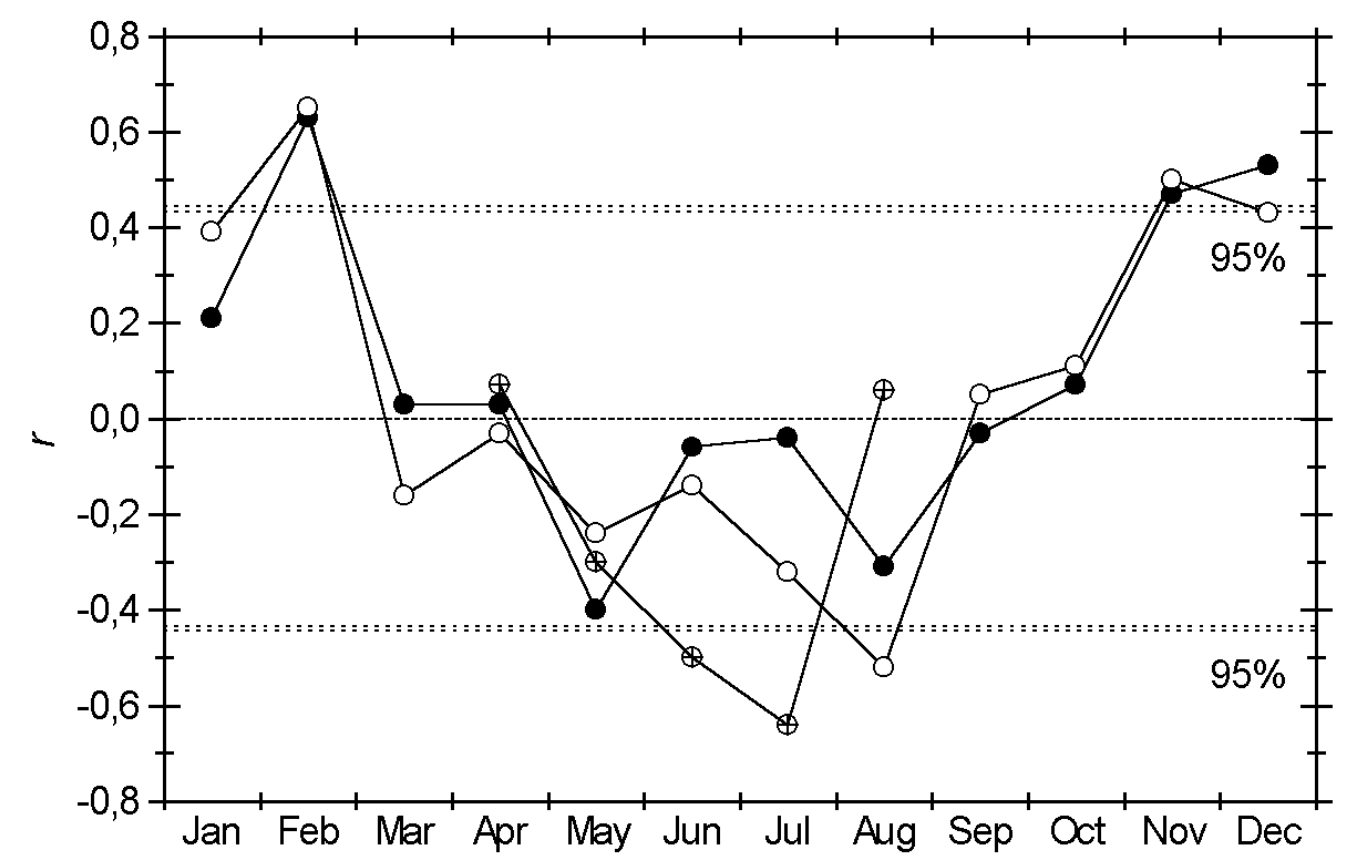

Figure 3: Solid symbols: correlation coefficients $r$ between monthly mean Collm zonal prevailing winds $v_{o z}$ and the SOI for each month of the year. Open symbols: correlation coefficients between the year-to-year differences of SOI and $v_{o z}$ in the respective months. Crossed symbols: correlation coefficients between the year-to-year differences of SOI in the respective months and $v_{o z}$ one month later. Period used is 1979 1999. The 95\% significance level is indicated by the dotted lines (t-test).

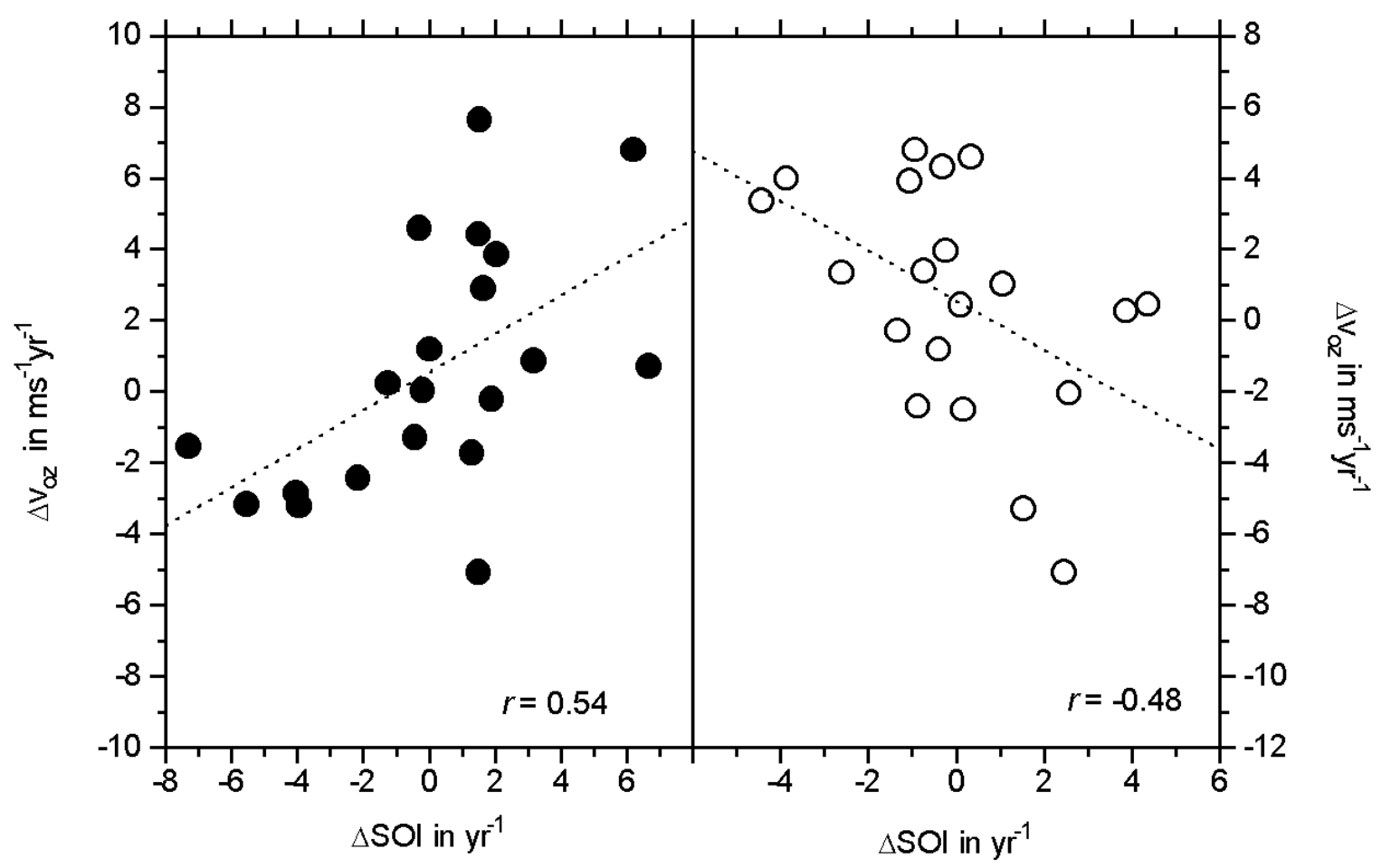

Figure 4: Year-to-year difference of zonal prevailing wind in winter (DJF, left panel) and summer (JJA, right panel) vs. year-to-year difference of SOI. 
In Figure 4 these year-to-year differences of the Collm MLT $\mathrm{v}_{\mathrm{oz}}\left(\Delta \mathrm{v}_{\mathrm{oz}}\right)$ are presented vs. the respective SOI differences $(\Delta \mathrm{SOI})$ for winter (DJF) and summer (JJA). The correlation is positive in winter, which can be expected if the reaction of the stratosphere on warm events (corresponding to small SOI) is taken into account: the stratospheric vortex is weaker due to an intensified Aleutian high (van Loon and Labitzke, 1987), which leads to weaker westerly winds in the mesosphere and also lower thermosphere. Therefore a positive correlation of SOI and $\mathrm{v}_{\mathrm{oz}}$ is expected. In summer, however, the correlation is negative, although it is not too strong $(r=-0.48)$. However, if we correlate May - July mean values of SOI with June - August means of $\mathrm{v}_{\mathrm{oz}}$ to take into account a possible delay due to the travel time of wave propagation, the correlation strengthens ( $r=-0.53$, not shown in the figure).

\subsection{Planetary wave propagation and $S O$ in summer}

The possible negative correspondence of summer SOI and MLT zonal winds seen in the right panel of Figure 4 cannot be explained by a simple decrease of the pressure level height gradient between high and equatorial latitudes during cold events (high SOI values). This would lead to a weaker strato-mesospheric easterly jet and in the MLT, i.e. above the wind reversal (Figure 1) to a stronger westerly wind, so that a positive connection would be the result. In addition, we compared the zonal mean summer $30 \mathrm{hPa}$ temperatures at $15^{\circ} \mathrm{N}$ near the equator with the SOI using year-to-year differences to avoid the influence of the negative stratospheric temperature trend (e.g. Keckhut et al., 1999). We found a weak negative correlation ( $r=-0.34,-0.56,-0.38$ for June, July and August, respectively) which would mean that during cold events (high SOI) the low-latitude zonal mean stratospheric temperature is lower and thus the latitudinal pressure gradient should be even stronger, if there is any connection.

We assume, however, that the negative connection seen in Figure 3 could be owing to varying PW propagation during the different phases of the SO. If we hypothesise that during cold events either westward travelling PW are more effectively forced or the propagation of part of the westward travelling waves through the stratosphere is facilitated, in the mesosphere and lower thermosphere this would lead to a westward directed acceleration of the mean flow through wave-mean flow interaction. This would mean that in the MLT region the easterlies (below $90 \mathrm{~km}$ altitude, see Figure 1) are stronger or the westerlies above $90 \mathrm{~km}$ altitude are weaker, as is the case over Collm (Figure 4). In principle, PW with comparatively short periods as the Rossby quasi 5-day wave, which have higher phase velocity, are more easily able to tunnel through the strato-/mesospheric easterlies in summer. However, a considerable part of the summer PW with short periods are due to atmospheric instability of the mesosphere, as is the case with the quasi 2-day wave (see Plumb, 1983). Meyer and Forbes (1997) proposed that a 6.5-day westward propagating wave is owing to atmospheric instability, too. Therefore investigating short-period (less than 10 days) PW might be misleading, and we consider the quasi 16-day Rossby PW here.

A measure for the activity of the quasi-16-day wave is the standard deviation $\sigma_{12-25}$ of the daily mean winds at Collm. Daily zonal and meridional mean wind values are calculated similar to the monthly means, but using half-hourly winds of only one day. The time series being filtered in the period range 12 - 25 days using a Lanczos filter (see, e.g., Thomson and Chow, 1980) with 100 weights. From the filtered time series daily values of the standard deviations $\sigma_{z, 12-25}$ and $\sigma_{\mathrm{m}, 12-25}$ of the zonal and meridional prevailing wind are calculated using a 32-day time interval each, and the respective values are attributed to the centre of the interval. 
From these data 3-monthly means can be calculated. The procedure is described in Jacobi et al. (1998). The total standard deviation is calculated after:

$$
\sigma_{12-25}=\sqrt{\sigma_{\mathrm{z}, 12-25}^{2}+\sigma_{\mathrm{m}, 12-25}^{2}}
$$

JJA time series of $\sigma_{12-25}$ and SOI are shown in Figure 5. No clear connection can be seen, which is probably due to two reasons.

Firstly, during the westerly phase of the equatorial quasi-biennial oscillation (QBO) westward travelling PW may propagate through the equatorial waveguide to the summer lower thermosphere (Dickinson, 1968). Jacobi et al. (1998) have found the QBO signal in the PW activity of the summer MLT over Collm. This wave activity may be stronger than the relatively weak signal due to the SO and may cover the correspondence. Therefore, to clearly show the possible process, only QBO east years should be selected. These are marked by the solid symbols in the SOI time series in Figure 5.

Secondly, volcanic eruptions like the ones of El Chichon in 1982 and the Pinatubo in 1991 lead to a strong warming on the lower stratosphere due to increased absorption then (Angell, 1993; Labitzke et al., 1997). Therefore the SO signal in the stratosphere is not found in the year after the eruptions, as was reported by Labitzke and van Loon (1989). The years of the eruptions are marked by big solid symbols in the PW activity time series in Figure 5.

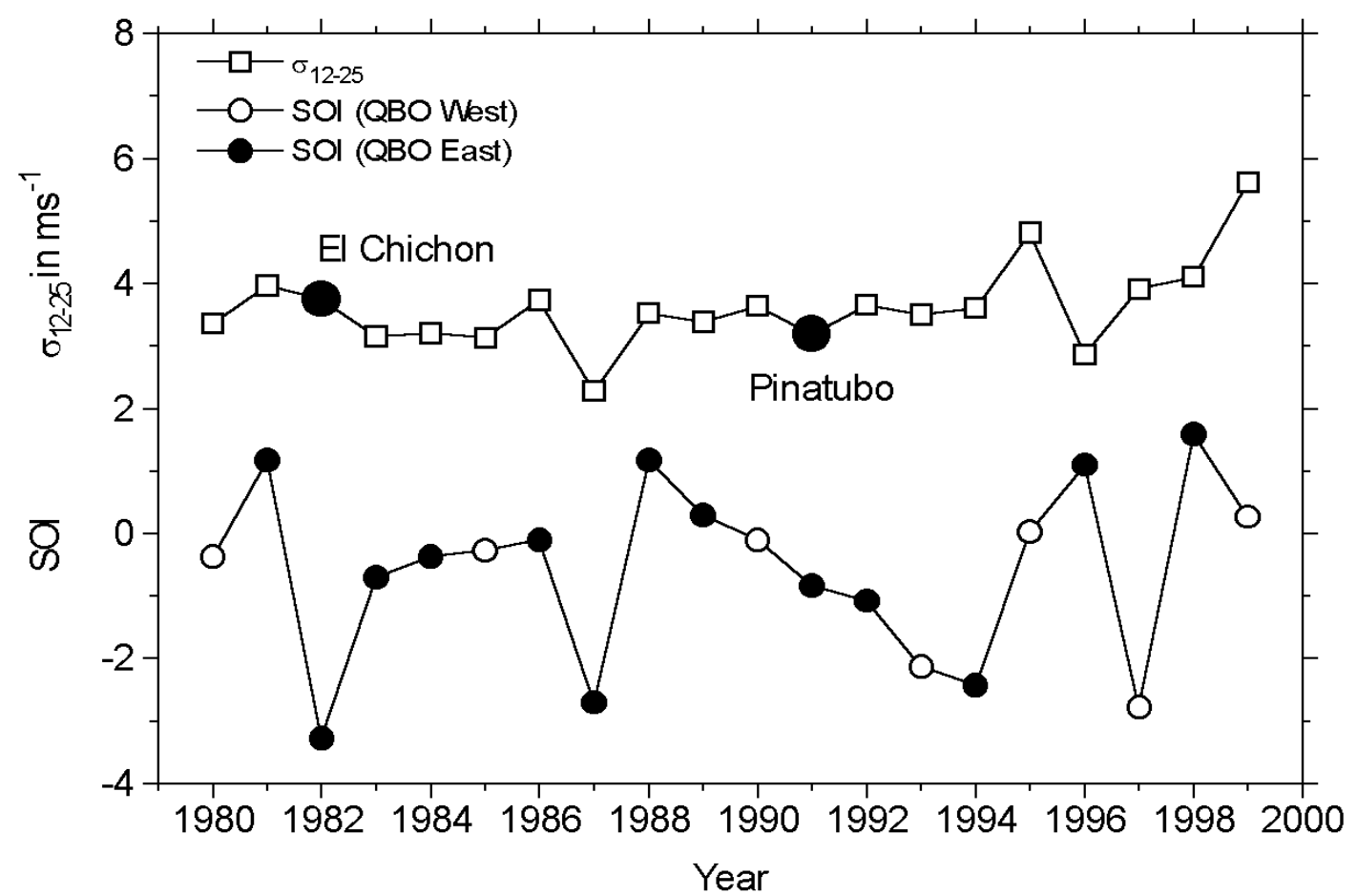

Figure 5: Time series of summer (JJA) prevailing wind standard deviation $\sigma_{12-25}$ in the 12-25 days range and of the SOI. QBO east years are indicated by a solid symbol of SOI. Thick solid symbols for $\sigma_{12-25}$ show years that are probably influenced by volcanic eruptions. 


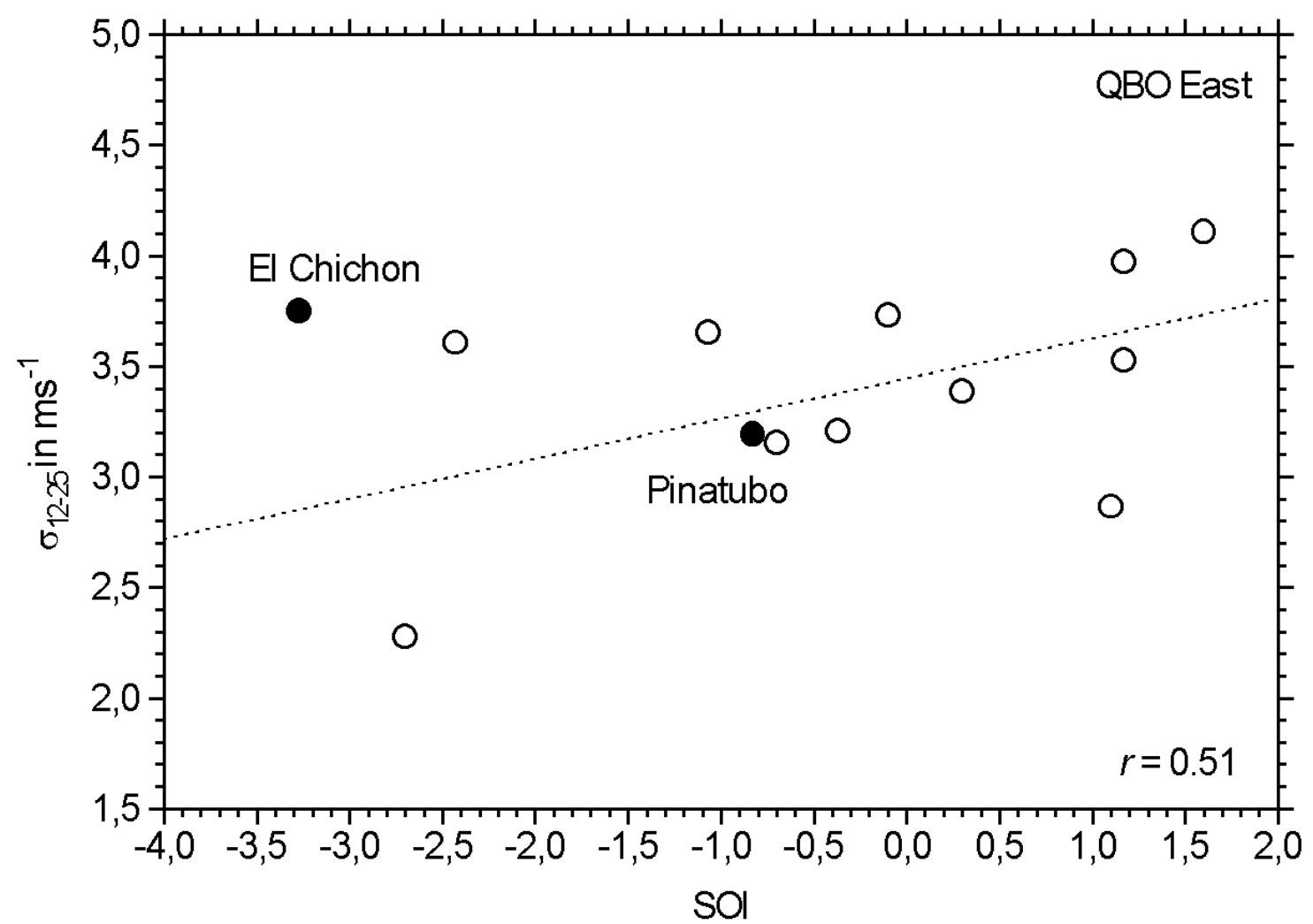

Figure 6: 12-25 day standard deviation of Collm JJA prevailing wind vs. SOI for QBO east years. Solid symbols are years probably influenced by volcanic eruptions.

If we present the $\sigma_{12-25}$ and SOI date for QBO east years in a scatter plot, as it is done in Figure 6, we find an indication for a correlation between these parameters so that, as expected, the PW activity is slightly enhanced during high SOI years. This is also the case with the stratospheric planetary waves. In the upper panel of Figure 7 the correlation coefficients $r$ between the monthly mean amplitude of the stratospheric height wave of zonal wavenumber 1 and the SOI is presented. The 3-monthly mean wave amplitudes were calculated from daily regression analyses of $30 \mathrm{hPa}$ gridded FU Berlin stratospheric pressure level height data at the respective latitudes. In the lower panel of Figure 7 the 1980 - 1999 mean amplitudes are shown. It can be seen that the correlation coefficients are positive at those latitudes where the amplitudes are strongest, which is in accordance with the Collm MLT results in Figure 6.

It should be noted that the stratospheric data are calculated from radiosonde ascents performed once a day, so that the data may contain the information of the diurnal tide in the stratosphere. However, diurnal tidal amplitudes are maximum at lower latitudes (e.g. Forbes, 1982; Khattatov et al., 1997; Geller et al., 1997; Hagan et al., 1999) while the maximum mean amplitudes in Figure 7 are found at high latitudes. Therefore we conclude that at least a considerable part of the height wave 1 is owing to PW activity.

\section{Conclusions}

Investigation of monthly Collm MLT zonal winds and SOI show that there is a relationship between the SO and the MLT region, which in winter corresponds to the reaction of the stratosphere to the SO (van Loon and Labitzke, 1987), so that stronger westerly winds are 
found during years of high SOI. This is also in correspondence with results from the Japanese MU radar that has been presented by Gavrilov et al. (1999).

In summer, Collm MLT zonal winds are negatively correlated to the SOI, while the strongest correlation is found in connection with a phase delay of one month between the SOI and the MLT winds. The connection between SOI and summer MLT winds may be explained by an influence of the SO on the PW propagation conditions in the middle atmosphere, which again force the MLT winds through wave-mean flow interaction. However, the Collm results for the summer months are not in correspondence with the Japanese radar results by Gavrilov et al. (1999). They have found stronger easterly winds during a period of El Niño. However, if we detrend the time series of Collm summer winds in the upper panel of Figure 2, we find, as is the case with the MU radar winds (Gavrilov et al., their Figure 1) that there is a general tendency towards weaker thermospheric westerlies (which correspond to stronger mesospheric easterlies) in the early 1990 s over both stations. This general tendency is filtered out when regarding only year-to-year variations as done in Figure 4. So possibly there are further processes acting on different time scales that influence the MLT region.

We also have to be aware that the SO in the summer stratosphere is only a weak signal compared, e.g., to the QBO that is the strongest circulation pattern in the tropical stratosphere (e.g. Naujokat, 1986). Therefore PW propagation in the equatorial stratosphere is much more strongly influenced by the QBO than by the SO. Even if we select cases with one particular QBO phase as we did in Figure 7, this does not totally exclude the influence of the QBO. Therefore it is clear that any SO influence on the MLT region must be weak.

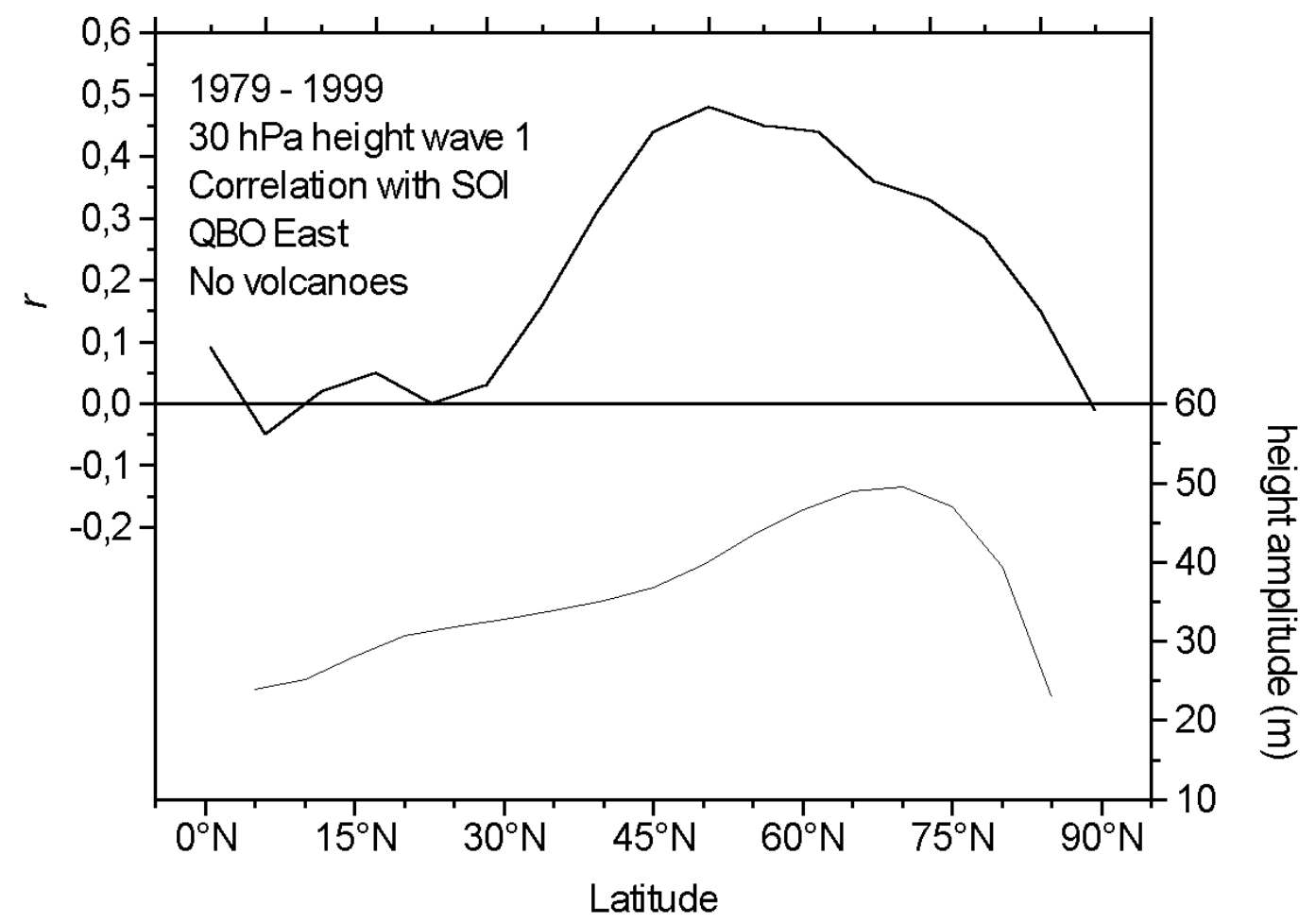

Figure 7: Correlation coefficients $r$ between JJA 3-monthly mean $30 \mathrm{hPa}$ height wave 1 amplitudes and the SOI (upper panel) and monthly mean height wave 1 (lower panel) vs. latitude. 
We stress again that results from one single point measurement not necessarily are valid for the entire MLT region and regional differences may be present. Jacobi et al. (2000) have presented considerable differences in the year-to-year variation of MLT winds over Canada and Europe. Therefore the results from Collm winds alone can only be attributed to the MLT region over Europe. An extended analysis including a larger number of stations with wind measurements will have to be performed.

\section{Acknowledgements}

SOI data were contributed by the NCAR Climate Analysis Section through Internet access on ftp://ftp.cgd.ucar.edu/pub/shea/soi_dir/soi, 9 May 2000. Stratospheric pressure level height data were kindly contributed by the Stratospheric Research Group of the FU Berlin.

\section{References}

Angell, J.K., 1993: Comparison of stratospheric warming following Agung, El Chichon and Pinatubo volcanic eruptions. Geophys. Res. Lett. 20, 715 - 718.

Forbes, J.M., 1982: Atmospheric tides 1. Model description and results for the solar diurnal component. J. Geophys. Res. 87, 5222 - 5240.

Gavrilov, N.M., S. Fukao, and T. Nakamura, 1999: Peculiarities of interannual changes in the mean wind and gravity wave characteristics in the mesosphere over Shigaraki, Japan. Geophys. Res. Lett. 26, 2457 - 2460.

Geller, M.A., V.A. Yudin, B.V. Khattatov, and M.E. Hagan, 1997: Modeling the diurnal tide with dissipation derived from UARS/HRDI measurements. Ann Geophysicae 15, 11981204

Hagan, M. E., M. D. Burrage, J. M. Forbes, J. Hackney, W. J. Randel, and X. Zhang, 1999: GSWM-98: Results for migrating solar tides. J. Geophys. Res. 104, 6813-6828.

Hedin, A.E., E.L. Fleming, A.H. Manson, F.J. Schmidlin, S.K. Avery, R.R. Clark, S.J. Franke, G.J. Fraser, T. Tsuda, F. Vial, and R.A. Vincent, 1996: Empirical wind model for the upper, middle and lower atmosphere. J. Atmos. Terr. Phys. 58, 1421 - 1447.

Jacobi, Ch., R. Schminder, and D. Kürschner, 1997: Measurements of mesopause region winds over Central Europe from 1983 through 1995 at Collm, Germany. Contrib. Atmos. Phys. 70, 189 - 200.

Jacobi, Ch., R. Schminder, und D. Kürschner, 1998: Long-period (12-25 days) oscillations in the summer mesopause region as measured at Collm $\left(52^{\circ} \mathrm{N}, 15^{\circ} \mathrm{E}\right)$ and their dependence on the equatorial quasi-biennial oscillation. Contrib. Atmos. Phys. 71, 461 - 464.

Jacobi, Ch., Yu.I. Portnyagin, T.V. Solovjova, P. Hoffmann, W. Singer, A.N. Fahrutdinova, R.A. Ishmuratov, A.G. Beard, N.J. Mitchell, H.G. Muller, R. Schminder, D. Kürschner, A.H. Manson, und C.E. Meek, 1999: Climatology of the semidiurnal tide at $52^{\circ} \mathrm{N}-56^{\circ} \mathrm{N}$ from ground-based radar wind measurements 1985 - 1995. J. Atmos. Solar-Terr. Phys. 61, 975 - 991.

Jacobi, Ch., M. Lange, D. Kürschner, A.H. Manson, and C.E. Meek, 2000: A long-term comparison of Saskatoon MF radar and Collm LF D1 mesosphere-lower thermosphere wind 
measurements. IAGA Workshop "Lower atmosphere effects on the ionosphere and upper atmosphere"; Prague, 25 - 27.7.2000, submitted to Phys. Chem. Earth.

Kane, R.P., C.E. Meek, and A.H. Manson, 1999: Quasi-biennial and higher-period oscillations in the mean winds in the mesosphere and lower thermosphere over Saskatoon, $52^{\circ} \mathrm{N}$, $107^{\circ}$ W. J. Geophys. Res. 104, 2645 - 2652.

Keckhut, P., F.J. Schmidlin, A. Hauchecorne, and M.L. Chanin, 1999: Stratospheric and mesospheric cooling trend estimates from U.S. rocketsondes at low latitude stations $\left(6^{\circ} \mathrm{S}\right.$ $34^{\circ} \mathrm{N}$ ), taking into account instrumental changes and natural variability. J. Atmos. SolarTerr. Phys. 61, 447 - 459.

Khattatov, B.V., M.A. Geller, and V.A. Yubin, 1997: Diurnal migrating tide as seen by the high-resolution Doppler imager / UARS. 2. Monthly mean global zonal and vertical velocities, pressure, temperature, and infrared dissipation. J. Geophys. Res. 102, 4423 4435 .

Kürschner, D., and R. Schminder, 1986: High-atmosphere wind profiles for altitudes between 90 and $110 \mathrm{~km}$ obtained from D1 FL wind measurements over Central Europe in 1983/1984. J. Atmos. Terr. Phys. 48, 447 - 453.

Kürschner, D., R. Schminder, W. Singer, and J. Bremer, 1987: Ein neues Verfahren zur Realisierung absoluter Reflexionshöhenmessungen an Raumwellen amplitudenmodulierter Rundfunksender bei Schrägeinfall im Langwellenbereich als Hilfsmittel zur Ableitung von Windprofilen in der oberen Mesopausenregion. Z. Meteorol. 37, 322 - 332.

Labitzke, K., 1999: Die Stratosphäre. Springer, Berlin, 177p.

Labitzke, K., and H. van Loon, 1989: The Southern Oscillation. Part IX: the influence of volcanic eruptions on the Southern Oscillation in the stratosphere. J. Clim. 2, 1223 - 1226.

Labitzke, K., S. Leder, and H. van Loon, 1997: The effect on the lower stratosphere of three volcanic eruptions. NCAR Tech. Note 433+PROC, Boulder, Colorado, 153 - 165.

Meyer, C.K., and J.M. Forbes, 1997: A 6.5-day westward propagating planetary wave: Origin and characteristics. J. Geophys. Res. 102, 26173 - 26178.

Namboothiri, S.P., A.H. Manson and C.E. Meek, 1993: Variations of mean winds and tides in the upper middle atmosphere over a solar cycle, Saskatoon, Canada, 52\#\#\#, 107\#\#\#W. J. Atmos. Terr. Phys. 55, 1325 - 1334.

Namboothiri, S.P., C.E. Meek and A.H. Manson, 1994: Variations of mean winds and solar tides in the mesosphere and lower thermosphere over time scales ranging from 6 months to 11 yr: Saskatoon, 52\#\#\#, 107\#\#\#W. J. Atmos. Terr. Phys. 56, 1313 - 1325.

Naujokat, B., 1986: An update of the observed quasi-biennial oscillation of the stratospheric winds over the tropics. J. Atmos. Sci. 43, 1873 - 1877.

Plumb R.A., 1983: Baroclinic instability of the summer mesosphere: A mechanism for the quasi-two-day wave? J. Atmos. Sci. 40, 262 - 270.

Portnyagin, Yu.I., 1986: The climatic wind regime in the lower thermosphere from meteor radar observations. J. Atmos. Terr. Phys. 48, 1099 - 1109. 
Portnyagin, Yu.I., J.M. Forbes, G.J. Fraser, R.A. Vincent, S.K. Avery, I.A. Lysenko and N.A. Makarov, 1993: Dynamics of the Antarctic and Arctic mesosphere and lower thermosphere regions - I. The prevailing wind. J. Atmos. Terr. Phys. 55, 827 - 841.

Ropelewski, C.F., and P.D. Jones, 1987: An extension of the Tahiti-Darwin Southern Oscillation Index. Mon. Wea. Rev. 115, 2161 - 2165.

Schminder, R. and D. Kürschner, 1994: Permanent monitoring of the upper mesosphere and lower thermosphere wind fields (prevailing and semidiurnal tidal components) obtained from LF D1 measurements in 1991 at the Collm Geophysical Observatory. J. Atmos. Terr. Phys. 56, 1263 - 1269.

Schminder, R., Ch. Jacobi, D. Kürschner, P. Hoffmann, D. Keuer, and W. Singer, 1997: The upper mesosphere and lower thermosphere wind field over Central Europe from 1994 through 1996 obtained from a joint analysis of LF windprofiler and MF radar measurements. Meteorol. Z., N.F. 6, 225 - 229.

Sprenger, K. and R. Schminder, 1969: On some relationships between the correlation analysis and similar-fade analysis results of drift measurements in the lower ionosphere. J. Atmos. Terr. Phys. 31, 1085 - 1098.

Thomson, R.E., and K.Y. Chow, 1980: Butterworth and Lanczos-window cosine filters with application to data processing on the UNIVAC 1106 computer. Institute of Ocean Sciences, Sidney, B.C., Pacific Marine Science Report 80-9.

Trenberth, K.E., 1984: Signal versus noise in the Southern Oscillation. Mon. Wea. Rev. 112, $326-332$.

Van Loon, H., and K. Labitzke, 1987: The Southern Oscillation. Part V: The anomalies in the lower stratosphere of the northern hemisphere in winter and a comparison with the quasibiennial oscillation. Mon Wea Rev. 115, 357 -369.

\section{Addresses of Authors}

Ch. Jacobi, Institut für Meteorologie, Universität Leipzig, Stephanstr. 3, 04103 Leipzig

D. Kürschner, Institut für Geophysik und Geologie, Universität Leipzig, Observatorium Collm, 04779 Wermsdorf 